\title{
Allometry of sexual size dimorphism in turtles: A comparison of mass and length data
}

\author{
Koy W. Regis ${ }^{1}{ }^{\text {, Jesse M. Meik }}{ }^{\text {Corresp. } 1}$ \\ ${ }^{1}$ Department of Biological Sciences, Tarleton State University, Stephenville, Texas, United States \\ Corresponding Author: Jesse M. Meik \\ Email address: meik@tarleton.edu
}

Background. The macroevolutionary pattern of Rensch's Rule (positive allometry of sexual size dimorphism) has had mixed support in turtles. Using the largest carapace length dataset and only largescale body mass dataset assembled for this group, we determine (a) whether turtles conform to Rensch's Rule at the order, suborder, and family levels, and (b) whether inferences regarding allometry of sexual size dimorphism differ based on choice of body size metric used for analyses.

Methods. We compiled databases of mean body mass and carapace length for males and females for as many populations and species of turtles as possible. We then determined scaling relationships between males and females for average body mass and straight carapace length using traditional and phylogenetic comparative methods. We also used regression analyses to evalutate sex-specific differences in the variance explained by carapace length on body mass.

Results. Using traditional (non-phylogenetic) analyses, body mass supports Rensch's Rule, whereas straight carapace length supports isometry. Using phylogenetic independent contrasts, both body mass and straight carapace length support Rensch's Rule with strong congruence between metrics. At the family level, support for Rensch's Rule is more frequent when mass is used and in phylogenetic comparative analyses. Turtles do not differ in slopes of sex-specific mass-to-length regressions and more variance in body size within each sex is explained by mass than by carapace length.

Discussion. Turtles display Rensch's Rule overall and within families of Cryptodires, but not within Pleurodire families. Mass and length are strongly congruent with respect to Rensch's Rule across turtles, and discrepancies are observed mostly at the family level (the level where Rensch's Rule is most often evaluated). At macroevolutionary scales, the purported advantages of length measurements over weight are not supported in turtles. 
1 ALLOMETRY OF SEXUAL SIZE DIMORPHISM IN TURTLES: A COMPARISON OF

2 MASS AND LENGTH DATA

3 Koy W. Regis ${ }^{1}$ and Jesse M. Meik ${ }^{1,2}$

$4{ }^{1}$ Department of Biological Sciences, Tarleton State University, Box T-0100, Stephenville, TX

576402 , USA

6

7 Corresponding Author:

8 Jesse M. Meik

9 E-mail address: meik@tarleton.edu (JMM) 
10 Abstract

11 Background. The macroevolutionary pattern of Rensch's Rule (positive allometry of sexual size dimorphism) has had mixed support in turtles. Using the largest carapace length dataset and only large-scale body mass dataset assembled for this group, we determine (a) whether turtles conform to Rensch's Rule at the order, suborder, and family levels, and (b) whether inferences regarding allometry of sexual size dimorphism differ based on choice of body size metric used for analyses.

17 Methods. We compiled databases of mean body mass and carapace length for males and females for as many populations and species of turtles as possible. We then determined scaling relationships between males and females for average body mass and straight carapace length using traditional and phylogenetic comparative methods. We also used regression analyses to evalutate sex-specific differences in the variance explained by carapace length on body mass.

Results. Using traditional (non-phylogenetic) analyses, body mass supports Rensch's Rule, whereas straight carapace length supports isometry. Using phylogenetic independent contrasts, both body mass and straight carapace length support Rensch's Rule with strong congruence between metrics. At the family level, support for Rensch's Rule is more frequent when mass is used and in phylogenetic comparative analyses. Turtles do not differ in slopes of sex-specific mass-to-length regressions and more variance in body size within each sex is explained by mass than by carapace length.

Discussion. Turtles display Rensch's Rule overall and within families of Cryptodires, but not within Pleurodire families. Mass and length are strongly congruent with respect to Rensch's Rule across turtles, and discrepancies are observed mostly at the family level (the level where Rensch's Rule is most often evaluated). At macroevolutionary scales, the purported advantages of length measurements over weight are not supported in turtles. 


\section{Introduction}

Body size is among the most frequently used variables in large-scale macroecological and evolutionary studies because it is a fundamental property of organisms relevant to physiology, ecology, anatomy, extinction risk, and genomic architecture (Peters, 1986; Calder, 1996; Cardillo et al., 2005; Lynch, 2007). However, despite its transcendent importance to nearly every aspect of biology, exactly what body size is remains unclear. Researchers often infer body size as a linear measurement based on anatomical landmarks, for example wing chord length in birds (Gosler et al., 1998); snout-vent length in most amphibians and reptiles, total length in others (Olalla-Tárraga \& Rodríguez, 2007; Meiri, 2010), and various other linear measurements are often used among invertebrates. To other researchers, body size is equated with some other physical property such as mass or volume. More recently, advances in geometric morphometrics have allowed 3-dimensional assessments of size and shape of biological structures (Chiari et al., 2008). The breadth of measurements used for body size brings the question of whether body size should be perceived as a real attribute, for which each of these variables might capture some aspects, or simply as an abstraction for which any of these subordinate concepts are interchangeable. On one hand, the frequent use of words such as "surrogate" or "proxy" in reference to the relationship between these measurements and body size implies that body size is perceived as a real latent variable. On the other hand, a widespread lack of interest or discussion about how well each of these variables might correspond to "true" body size implies an abstract conception of body size. Likewise, the frequent practice of combining different measurements of body size for the same analyses implies that at least empirically body size is often perceived as an abstract variable, with the justification being that the suites of variables used to infer body size are strongly correlated. However, strong correlations between variables do not necessarily ensure that they will yield the same statistical or biological inferences when used as proxies for each other. For example, the body size frequency distribution for a sample of squamate reptiles was found to be bimodal when length was used but was unimodal in a larger sample of lengthderived mass estimates (Cox et al., 2011; Feldman et al., 2016).

Assuming that body size is a real attribute that is universal across life, to what extent does each of these surrogate measurements approximate this property? Sometimes an argument is presented to justify a particular measurement over others, but ultimately the proxies for body size most often selected seem to be based on convention or convenience (Houle, 2011; and e.g., Iverson, 1982; Gibbons \& Lovich, 1990). Most types of linear measurements are of limited value in that they often are restricted to single taxa. Furthermore, each length measurement reflects selection on body size through allometric growth, and each anatomical feature may be subject to its own selective pressures and constraints, independent of or in conjunction with overall body size (Andersson, 1994).

If the underlying causes of body size relate to energetics of metabolism (i.e., metabolic theory; Gillooly et al., 2001; Brown et al., 2004), then mass might hold unique status as a proxy for body 
size because it will more accurately reflect the amount of matter (i.e., number of cells) that must be organized and maintained by living systems. Mass also can be measured and directly compared across all clades, which makes it a particularly desirable variable for macroecological studies. These may be reasons why researchers often interpolate mass datasets from regression equations based on limited mass and length data, which we hereafter refer to as length-derived mass data (LDM data; Pough, 1980; Iverson, 1982; Meiri, 2010; Burbrink \& Myers, 2014). Although mass data are often collected for amphibians and non-avian reptiles, snout-vent length (or carapace length for turtles) is far more frequently reported and equated with body size. Mass data are often assumed to be more prone to fluctuations in body condition, digestive state, health, and reproductive status (Stamps, 1983; Cox et al., 2007; Bonnet et al., 2010), and these assumptions are frequently supported with intraspecific datasets (e.g., Jacobson et al., 1993; Nagy et al., 2002; Stevenson \& Woods, 2006). However, there is little empirical information addressing the relative variability of mass and length data at macro-scales, especially for nonavian reptiles, as most researchers focus on obtaining only one measurement of body size for macroevolutionary datasets. Moreover, the variability of a measurement does not necessarily indicate its appropriateness as a surrogate for body size. Biological conditions such as reproductive condition or starvation could be important (albeit transient) aspects of body size, at least physiologically.

As an empirical test of the congruency of mass and length body size data, we here evaluate inferences from each of these size metrics as they relate to the macroevolutionary pattern of Rensch's Rule (Rensch, 1950) in turtles (clade Chelonia). Rensch's Rule (RR) describes an allometric scaling relationship in body size where among closely related species, the size difference between males and females increases with overall body size in species where the males are the larger sex. When females are the larger sex, RR predicts sexual size dimorphism (SSD) to diminish as overall species body size increases.

Rensch's Rule has been widely studied in diverse taxa such as plants, arthropods, reptiles (including birds), and mammals (reviewed in Fairbairn, 1997). Support for the pattern is varied but is most often reported in male size-biased taxa, where sexual selection on males for larger size combined with genomic covariation between the sexes is assumed to result in the pattern (Fairbairn \& Preziosi, 1994). This hypothesis also implies that large body size may result generally from male-biased size dimorphism. However, support for the pattern is less often found in female size-biased lineages (which comprise the majority of sexually dimorphic lineages), and the relative contributions of sexual selection and fecundity selection on body size in female size-biased lineages are less resolved (Webb \& Freckleton, 2007). If a lineage displays the converse of RR, with strongly female size-biased species at larger overall sizes, then fecundity selection (perhaps together with antagonistic sexual selection for smaller males that could partition more of their energy budgets into mate-searching rather than growth) is often assumed to play a major role in SSD and body size in that group. 
110 Studies of RR have used many different measurements of body size, usually whichever proxy of

111

112

113

114

115

116

117

118

119

120

121

122

123

124

125

126

127

128

129

130

131

132

133

134

135

136

137

138

139

140

141

142

143

144

145

146

147

148 body size is most readily available for the taxon in question, and by doing so potentially equate disparate measurements as body size. Which type of measurement, and therefore implicit definition of body size, to use for analyses of RR has been a recurring issue in studies of SSD (Lovich et al., 1990; Fairbairn et al., 2007). For example, Székely et al. (2007) examined sexual dimorphism in body mass, wing length, tarsus length, bill length, and tail length in birds and found only weak correlations between these traits with respect to SSD. Despite these concerns, few studies have directly compared length measurements with mass data to determine whether they would yield different inferences relating to body size dimorphism (but see Rising \& Somers, 1989; Gibbons \& Lovich, 1990). The uncertainty of how to define body size as it relates to RR is as old as the hypothesis, because in Rensch's seminal work (1950), both length and mass data were combined in the same analyses to formulate RR.

Turtles are a model clade for which to study body size and SSD, as both attributes vary dramatically across lineages. Turtles include about 330 extant species, and individual species range in size from the diminutive speckled tortoise, Homopus signatus (Gmelin, 1789), attaining weights of $\sim 130 \mathrm{~g}$ and carapace lengths up to $9 \mathrm{~cm}$ (Loehr, 2001), to the leatherback sea turtle, Dermochelys coriacea (Vandelli, 1761), one of the largest extant reptiles, attaining weights of at least $650 \mathrm{~kg}$ and curved carapace lengths of over $2.1 \mathrm{~m}$ (McClain et al., 2015). The standard body size measurement in turtles is the taxon-specific straight carapace length (SCL), a linear measurement of the dorsal shell. When using carapace length, size comparisons between turtles and other groups are possible only through LDM data based on allometric regression equations of limited value (e.g., Pough, 1980). Carapace length often is lauded as a stable measurement of size across turtles, with little or no apparent seasonal or daily variation. However, species vary, especially by family, in the relative size and shape of the shell when compared with other aspects of body size. Furthermore, there is often ambiguity in what is actually being measured with carapace length. Curved carapace length (the non-Euclidian-distance over the curve of the shell) is sometimes substituted for SCL in larger taxa (e.g., sea turtles) for practicality, but these measurements cannot be directly compared to straight carapace length, owing to interspecific differences in shell shape. There are at least three different methodologies for measuring straight carapace length in turtles (and two for curved carapace length) that differ with respect to the anatomical start and end points (Pritchard et al., 1983; Bolten, 1999), and researchers may neglect to disclose what they mean by "straight carapace length," or, even worse, "carapace length." In contrast, body mass is less ambiguous (although still subject to error) and is seemingly widely recorded (pers. obs), but unfortunately as with other non-avian reptiles, mass is rarely reported in turtles (Iverson, 1982).

Rensch's Rule within turtles has had mixed support from previous studies. Early studies were limited in their taxonomic and geographic scope and did not employ phylogenetic comparative methods (Berry \& Shine, 1980; Iverson, 1985; Gibbons \& Lovich, 1990). Those studies found support for RR in Kinosternidae, but not in turtles overall. More recent studies have varied in 
149

150

151

152

153

154

155

156

157

158

159

160

161

162

163

164

165

166

167

168

169

170

171

172

173

174

175

176

177

178

179

180

181

182

183

184

185

186

phylogenetic hypotheses, body size metrics (i.e., mean versus maximum length), and types of regression analyses, and have found support for either RR or for isometry (Cox et al., 2007; Stephens \& Wiens, 2009; Ceballos et al., 2013; Halámková et al., 2013; Werner et al., 2016). At the family level, the Kinosternidae has continued to attract attention, as different studies arrived at different conclusions (Ceballos \& Iverson, 2014). Most turtle species are female-biased in carapace length, but the RR pattern has been found most often in male size-biased taxa, so turtles are unusual in this respect (Ceballos et al., 2013). Despite the overall trend of female size-bias across turtles, the directionality of size dimorphism varies within most families, sometimes even within genera and species (Lovich et al., 2010). A recent study of spur-thighed tortoises (Testudo graeca) found that SSD was male-biased in populations with large body size and female-biased in populations with small body size, showing an intraspecific pattern consistent with RR (Werner et al., 2016). Although a variety of methodologies have been employed, all previous studies of SSD in turtles have used only carapace length as a size metric, and therefore we evaluate, for the first time, whether the choice of body size measurement (length or mass) affects inferences about $\mathrm{RR}$ in turtles.

\section{Materials \& Methods}

\section{Data Collection}

Data were compiled on average adult body mass and straight carapace length (SCL) for males and females for as many turtle species and populations as possible from primary literature, government agency reports, dissertations and theses, as well as unpublished sources. Body mass data came from 198 sources (Appendix S1). Data on SCL came mostly from the datasets of Ceballos et al. (2013) and Halámková et al. (2013), augmented with 122 sources that recorded both body mass and SCL (Appendix S1). For both datasets, data from captive populations were included to increase species coverage, but data on juveniles and gravid females were excluded when possible. Although captive turtles often exhibit different patterns of growth than do wild populations, common garden experiments indicate that the direction and magnitude of SSD are mostly consistent between captive and wild populations (Ceballos \& Valenzuela, 2011; Ceballos et al., 2014). Moreover, only seven of 146 species used for analyses of mass and four of 241 populations used for analyses of SCL were from captive populations; therefore, any influence of captivity would likely be minimal at the scale of our study. When only ranges of values were reported, the midpoint was calculated and used as average body size for both SCL and mass. In a few instances, maximum values were used if no averages were reported. Inferences from previous studies have been mixed as to whether maximum values yield similar results to mean values (e.g., Fitch, 1981; Lovich \& Gibbons, 1990; Boback and Guyer, 2003); however, once again maximum values constituted a small portion of our dataset (nine of 146 species for mass and 19 of 241 species for SCL). Two morphotypes (i.e., "saddlebacked" and "domed") of the Chelonoidis species complex of Galapagos tortoises were included in non-phylogenetic analyses, 
187

188

189

190

191

192

193

194

195

196

197

198

199

200

201

202

203

204

205

206

207

208

209

210

211

212

213

214

215

216

217

218

219

220

221

222

223

224

as populations of Chelonoidis nigra (Quoy \& Gaimard, 1824); we chose to retain this conservative taxonomy as recent nomenclatural changes for Galapagos tortoises have not yet stabilized. For three species (Apalone ferox, Kinosternum integrum, and Pseudemys gorzugi), we combined data on body mass of males and females from different sources, because no single study reporting body mass for both sexes could be found. Prior to all analyses, body mass and SCL were log-transformed. When we had data on more than one population of a species for both datasets, we randomly selected one population per species for analysis. However, when indicated, we also performed analyses using the full population-level datasets (i.e., multiple populations of some species).

As a preliminary assessment of trends in SSD across families, we calculated the commonly used index of Lovich and Gibbons (1992) for each species and present the means of these indices. This index is calculated as (larger sex/smaller sex) +1 if males are larger and -1 if females are larger, arbitrarily set as positive if females are larger and negative if males are larger. The index is symmetric around zero and comparable to a percent difference in size. We calculated the dimorphism index using log-transformed SCL and mass data. We present the mean of the ratios, not the ratio of the means, in order to illustrate uniformity or variability in directionality of dimorphism, and because the ratio of the means is overly influenced by the largest species.

\section{Analysis of Rensch's Rule}

Rensch's Rule typically is analyzed by regressing log-transformed male body size against logtransformed female body size (Fairbairn, 1997; Ceballos et al., 2013; Halámková et al., 2013). When log-female size is plotted on the $\mathrm{x}$-axis and log-male size is plotted on the $\mathrm{y}$-axis, positive allometry (a slope greater than one) represents a pattern consistent with RR, and negative allometry (a slope less than one) represents the converse of RR. A slope not significantly different from one represents isometry. Standardized major axis (SMA) regression was selected over ordinary least squares regression, as there is no a priori reason to suspect differences in measurement error between the sexes. We performed SMA regression using the package "smatr" (Warton et al., 2012) in R software version 3.2.0 (R Core Team, 2015). The 95\% confidence intervals (CI) of the regression slopes were calculated, with CI lower limit $>1$ indicating RR, CI upper limit $<1$ indicating the converse of RR, and a CI range that includes 1 indicating isometry. Rensch's Rule analyses were performed across all turtles and also performed at the suborder level (i.e., Cryptodira and Pleurodira) and at the family level (for families with data available for seven or more species).

To account for the differences in shared phylogenetic history among species, and as is standard for analyses of RR, we repeated our analyses using phylogenetic comparative methods after first testing the datasets for phylogenetic signal with Blomberg's $K$ statistic (Blomberg et al., 2003) using the R package "picante" (Kembel et al., 2010). A significant $K$-value indicates that a particular tree explains more variance than a star phylogeny, and therefore that phylogenetic comparative methods would be justified (i.e., non-independence of trait values in closely related 
225

226

227

228

229

230

231

232

233

234

235

236

237

238

239

240

241

242

243

244

245

246

247

248

249

250

251

252

253

254

255

256

257

258

259

260

species might influence regression parameters). A $K$-value of more than or less than 1 indicates that species resemble their relatives in that trait more or less, respectively, than would be expected under a Brownian motion model of evolution. Male body mass, female body mass, male SCL, and female SCL were each evaluated separately for $K$. The phylogeny used was an unpruned version of the turtle supertree from Angielczyk et al. (2015) provided by the authors. When polytomies occurred, they were broken into random dichotomies. We were able to match 145 species with body mass data and 241 species with carapace length data to the phylogeny. These data were transformed using phylogenetic independent contrasts (PIC) with the "ape" package (Paradis et al., 2004) in R. The PICs were then regressed using SMA regression, with the intercept fitted through the origin, as recommended by Garland et al. (2012). As with the non-phylogenetic regressions, the estimated slopes and their $95 \%$ confidence intervals were used to assess conformity to RR, its converse, or isometry.

\section{Mass-Carapace Length Relationships}

It is plausible, due to sexual selection on males or the metabolic and gestational constraints on reproduction in females, that growth could be partitioned differently between mass and length within sexes. Furthermore, if gravidity in females cannot reliably be detected by researchers in the field, females should show a more variable relationship between mass and length than males, which might add noise to macroevolutionary analyses. To determine if males and females differed in their relationships between body mass and SCL, their log-transformed SCLs were regressed against their log-transformed body masses, and then a Chow test (Chow, 1960) was performed to test for differences in the coefficients of determination of regressions of males and females combined and of males and females separately. We performed these analyses on all 208 populations for which data on male and female mass and SCL were available. We chose not to use phylogenetic analysis for this question and to include multiple populations for some species, as our purpose was simply to assess differences in variance explained by body size metrics between sexes.

\section{Results}

\section{Data Summary}

Body mass data included 307 populations representing 146 of the approximately 330 turtle species (van Dijk et al., 2014), and SCL data included 581 populations, representing 242 living species (Table 1; full dataset is included as Data S1). All fourteen turtle families were present in both datasets. Of the populations used for analysis of RR, males were heavier in 38 of 146 species $(26.0 \%)$, females were heavier in 104 species $(71.2 \%)$, and 4 species $(2.7 \%)$ had negligible SSD (i.e., $<2 \%$ difference). Similarly, males had longer carapaces in 66 of 242 
261

262

263

264

265

266

267

268

269

270

271

272

273

274

275

276

277

278

279

280

281

282

283

284

285

286

287

288

289

290

291

292

293

294

295

296

species $(27.3 \%)$, females had longer carapaces in 161 species $(66.5 \%)$, and 15 species $(6.2 \%)$ had negligible SSD. The direction of SSD generally was consistent at the family level between body mass and SCL, with the exception of families Pelomedusidae and Kinosternidae. As noted by Lovich and Gibbons (1992), the choice of mass or length data influences the perceived magnitude of SSD, and we observed that indices calculated from body mass were often, but not always, more extreme, than indices calculated from SCL (Table 1).

\section{Rensch's Rule Across Chelonia}

Without phylogenetic comparative methods, body mass and carapace length disagreed slightly regarding patterns of allometry in turtles (only in terms of the statistical threshold indicating allometry). Body mass $\left(n=146, r^{2}=0.858, P<0.001\right)$ showed positive allometry (RR; $b=$ $1.066 ; 95 \% \mathrm{CI}=1.002-1.135$; for $\left.\mathrm{H}_{0} b=1, P=0.042\right)$. Straight carapace length $\left(n=241, r^{2}=\right.$ $0.789, P<0.001)$ showed a marginally non-significant positive allometry $(b=1.057 ; 95 \% \mathrm{CI}=$ 0.997-1.120; for $\mathrm{H}_{0} b=1, P=0.064$ ), thus supporting isometry (Fig. 1).

Blomberg's $K$-values indicated that both body mass and SCL had moderate phylogenetic signal for each sex $(P$-values $<0.001)$. Male mass had the lowest $K$, at 0.545 , female mass was 0.604 , female carapace length was 0.619 , and male carapace length 0.636 , suggesting that mass has slightly more phylogenetic signal. However, the similar levels of phylogenetic signal in both sexes provides support for strong genetic correlation in body size between the sexes (Fairbairn, 1997). In the phylogenetic comparative analyses, conformity to RR was supported by both body mass and SCL with high congruence of regression parameter estimates (Fig. 2). The SMA regression for PICs of body mass had a slope of $1.099\left(n=145 ; 95 \% \mathrm{CI}=1.029-1.173 ; r^{2}=\right.$ 0.844; for $\left.\mathrm{H}_{0} b=1, P=0.0048\right)$, and the PICs for SCL had a slope of $1.093(n=241 ; 95 \% \mathrm{CI}=$ $1.029-1.16 ; r^{2}=0.773$; for $\left.\mathrm{H}_{0} b=1, P=0.0042\right)$.

\section{Rensch's Rule at Suborder and Family Level}

Despite the overall pattern of RR in turtles, positive allometry was not universal among turtle families. The choice of body size metric and whether phylogenetic comparative methods were employed both influenced inferences of SSD allometry in several turtle families. Using nonphylogenetic analyses, RR was not supported in the suborder Pleurodira or any of its families, suggesting the overall pattern of RR in turtles may result mostly from positive allometry in the Cryptodira suborder (Table 2). For body mass, we found support for RR in the suborder Cryptodira and in two of its families, Testudinidae and Trionychidae; however, using SCL we detected RR for only the family Testudinidae. All other non-phylogenetic regression slopes at the suborder and family level supported isometry (Table 2).

Rensch's Rule was more often detected in a phylogenetic context at the family level, particularly for body mass (Table 3). Using body mass, support for Rensch's Rule was found in

Geoemydidae and Kinosternidae, in addition to Testudinidae, Trionychidae, and Cryptodira 
297

298

299

300

301

302

303

304

305

306

307

308

309

310

311

312

313

314

315

316

317

318

319

320

321

322

323

324

325

326

327

328

329

330

331

332

333

overall. Using SCL, we found support for RR only in Testudinidae and Cryptodira overall. As with non-phylogenetic regressions, the remaining families demonstrated isometry.

\section{Mass-Carapace Length Relationships}

As expected, both males and females showed strong relationships between SCL and body mass when including all populations for which we had obtained data for both variables (including multiple populations of several species) (Fig. 3). For both sexes combined, $r^{2}$ was $0.932(n=$ $416 ; b=0.345, P<0.0001)$. Analyzed separately, $r^{2}$ was 0.910 for males $(n=208, b=0.338)$ and 0.954 for females $(n=208, b=0.341)$. Although females had slightly higher variance in SCL explained by body mass, neither the slopes $(P=0.5)$ nor the coefficients of determination (Chow test: $F=2.176, P=0.115$ ) were significantly different between the sexes.

\section{Discussion}

Our allometric analyses include the largest independent body mass and SCL datasets yet brought to bear on the question of RR in turtles. At the deepest phylogenetic scale, results show remarkable congruence in estimates of positive allometry for both body mass and SCL data (Fig. 2 ), and thus indicate that overall turtles follow RR. However, we noted some discrepancies in inferences of RR depending on analyses (non-phylogenetic vs. phylogenetic) and body size metric used, suggesting that these factors will partly influence the detection of patterns of allometry in SSD. Most discrepancies related to discerning a pattern of positive allometry from isometry at the family level, which is the level most often used in comparative studies of SSD (e.g., Cox et al., 2007; Székely et al. 2007; Ceballos \& Iverson, 2014). In contrast to some previous studies (e.g., Lindeman 2008; Ceballos et al. 2013), we found no support for a pattern converse to RR in any chelonian clades. With the mass dataset, we were able to detect RR in four families, rather than just Testudinidae as with the SCL dataset, despite that sample sizes were larger across all families for the SCL dataset. This result might be expected given that volume scales to the cube of linear measurements (under the simplistic assumption of isometry), and therefore differences in SSD will generally be more extreme with mass than with length datasets, as it is in turtles (Lovich \& Gibbons, 1992; Table 1). Although it would be tempting to conclude that SCL will give more conservative estimates of body size allometry, it is important to recognize that SCL and mass are different measures and therefore different results partly reflect underlying morphological and scaling differences in addition to differences in statistical power.

The potentially greater statistical power of body mass compared to SCL to detect allometry of SSD emphasizes differences in inferential capabilities that are inherent when using different measures of body size in macroevolutionary studies. These statistical issues likely will be more apparent in clades where SSD is moderate. For example, in our analyses the family Kinosternidae showed moderate female-biased SSD in body mass but moderate male-biased SSD in SCL (Table 1), and showed RR using body mass but isometry with SCL (Table 3). 
334 Previous studies using SCL data have found contrasting patterns for RR in Kinosternidae, (e.g.,

335 Berry and Shine 1980; Iverson 1985; Ceballos et al. 2013; Halámková et al. 2013), with Ceballos

336

337

338

339

340

341

342

343

344

345

346

347

348

349

350

351

352

353

354

355

356

357

358

359

360

361

362

363

364

365

366

367

368

369

370

371

372 and Iverson (2014) suggesting that different conclusions have resulted from use of different phylogenetic topologies in comparative analyses. We suggest that choice of body size metric will also influence inferences of RR, particularly in families with moderate or contrasting patterns of SSD. For Kinosternids, males are longer but weigh less than females (at the level of family means), and it is reasonable to assume that similar contrasting patterns of SSD are not uncommon across animals.

Our analyses of SSD in turtles indicate that use of both length and weight metrics would provide more comprehensive evaluation of size dimorphism across lineages, and that larger datasets for each type of metric would be more likely to converge on quantitatively similar inferences. Although carapace length is the most common body size metric for turtles, we've noted during the course of our data collection that mass is frequently recorded but rarely reported. In numerous instances, authors paradoxically state that they collected mass data for males and females and then never provide or even mention these data again, even in studies of body condition or SSD. However, this problem is not unique to turtles, as available measures of length predominate over mass in non-avian reptiles, generally. While we found that carapace length is likely an acceptable measurement in turtles, we expect that inferences from body size differences using other length measurements in other groups might be inadequate. Turtles are relatively constrained in body shape, whereas squamates are markedly labile. Snout-vent length (SVL) is approximately the length of the torso, but this measurement encapsulates little of the substantial variation in squamate body shape (Feldman \& Meiri, 2013). Partial limb reduction or limblessness has evolved many times in squamates (Wiens et al., 2006), tail autotomy is common, and the relationship between SVL (or total body length) and body mass differs dramatically between taxa (Pincheira-Donoso et al., 2011).

Body mass has certain advantages over measures of length as a body size metric. Unlike most measures of length, body mass is applicable to all organisms, and estimates do not rely on anatomical landmarks. While both mass and length can be estimated with various levels of precision, length measurements always require at least two anchor points and therefore have at least two components of error variance. Furthermore, body mass is more directly related to physiology, life history, and reproductive biology. The most often cited disadvantage of body mass is that it is purportedly more variable than length measurements owing to differences in body condition and in reproductive and digestive states. We see two problems with this line of reasoning. First, although the statement appeals to intuition because mass effectively compounds three linear dimensions, and therefore a coefficient of variation in mass that is three times higher than that of a single linear measurement would reflect similar precision (Calder, 1996), we know of no studies that have demonstrated that mass measures are more intrinsically variable than length measures at macroevolutionary scales. Most studies that invoke this reasoning are snapshot studies, and their samples do not represent temporal series that would reflect such 
373

374

375

376

377

378

379

380

381

382

383

384

385

386

387

388

389

390

391

392

393

394

395

396

397

398

399

400

401

402

403

404

405

406

407

408

409

410

411

variation with any type of body size metric anyway. In contrast to this typical argument, our data indicate that more variation in SCL is explained by body mass in females rather than in males. Given the assumption that for turtles it is difficult to assess gravidity reliably in the field, we would expect a priori that less variation would be explained by the relationship between SCL and mass in females than in males; therefore, our macro-scale datasets do not support the hypothesis that mass data are intrinsically more variable. Second, we question whether a more variable body size metric, one that reflects short-term fluctuations in body state, would be less informative than a more static body size metric.

Recognizing the many limitations of length datasets, particularly for larger-scale comparisons, several authors have explored the feasibility of interpolating body mass from allometric regressions of length datasets for various vertebrate groups, yielding LDM datasets (e.g., Pough, 1980; Iverson, 1982; Pincheira-Donoso et al., 2011; Feldman \& Meiri, 2013; Meiri et al., 2013; Feldman et al., 2016). These equations are based on the relatively small number of species for which body mass data are available, and as expected, accuracy of estimates will depend partly on the taxonomic scale for which data are generated (most recent interpolations of mass are based on family-specific regression equations). In many instances, vast datasets have been compiled based solely on the interpolations and associated assumptions of relatively few regression equations (e.g., O’Gorman \& Hone, 2012).

Although the additional data processing involved in generating LDM datasets might provide a suitable heuristic for some purposes, these calculated datasets should not be conflated with actual mass datasets (i.e., species-specific estimates of body mass generated from actual weights). In addition to relying on the assumption that mass and length are perfectly correlated, interpolations could magnify the compounded measurement error associated with length measurements without explaining any more variation. A more pernicious influence is that LDM data could be mistaken for genuine mass measurements by later workers (Smith \& Jungers, 1997), especially as citations for data points in large-scale analyses are increasingly relegated to unindexed appendices, if at all (Payne et al., 2012). Thus, while important inferences have been made from LDM data, we consider results from studies dependent on such datasets to be tenuous, and suggest that results of these studies should be verified with actual mass datasets as they become available. However, we also note that recent advances in computed tomography technology and volumetric modeling, as well as incorporating multiple anatomical correlates of mass, have allowed considerable refinements in weight estimation, particularly in applications to paleontological data (Field et al., 2013; Brassey \& Sellers, 2014; Brassey et al., 2016). For clarity, and because mass and length may point to different conclusions, we recommend that authors analyze the body size measurement that they have, in addition to any desired transformation (e.g. LDM).

While our analyses add to the evidence that the Chelonian clade overall displays the RR pattern of sexual size dimorphism, using either mass or carapace length, the ultimate meaning to be drawn from the allometric pattern remains unclear. The traditional interpretation of $R R$, that sexual selection for larger males drives body size evolution (Abouheif \& Fairbairn, 1997) in a 
412 (usually male size-biased) group, seems to bear little relevance to most turtle species, which are a 413 predominately female size-biased group. Moreover, the prevailing consensus that SSD in turtles

414 is caused by sex-specific differences in size at sexual maturity is somewhat tautological, and

415 does not indicate ultimate mechanisms involved in these growth differences (Gibbons \& Lovich,

416 1990; Lovich et al., 2014). With an ancestral female size-bias (Ceballos et al., 2013) and

417 approximately two-thirds of extant species retaining a female size-bias, ascribing sexual

418 selection for large males as the primary driving force of SSD in Chelonians is an

419 oversimplification. We found the most support (i.e., with and without phylogenetic comparative

420 methods) for RR in two families divergent in their morphologies, habitats, and ecologies: the

421 male size-biased Testudinidae and the female size-biased Trionychidae. It is not immediately

422 apparent how the various overlapping and often contrasting selective forces (e.g., fecundity

423 selection, sexual selection, energetic constraints) would conspire to produce the RR pattern in

424 these families and not in others. Whether the turtle families with an isometric pattern of SSD are 425 constrained by genomic covariation on body size, or display isometry as a result of other forces 426 on male and female size, cannot be answered from examination of RR alone. Rensch's Rule, or 427 his "conjecture" (see Webb \& Freckleton, 2007), has stimulated much research and discussion of 428 sexual size dimorphism. However, more precise hypotheses and more precise quantification of 429 intra- and interspecific selection forces on body size are needed to understand SSD.

430

431

432

433

434

435

436

437

438

439

440

441

442

443

444

\section{Acknowledgements}

We thank all the researchers whose work contributed to our data. Kenneth Angielczyk, Robert Burroughs, and Chris Feldman provided the phylogenetic tree used in our analyses. We thank Ben Anders for assistance with literature and for discussions on body size evolution in turtles. Robert Burroughs, Christian Cox, Kristin Herrmann, and Phil Sudman provided valuable comments on earlier drafts of this manuscript.

\section{SUPPORTING INFORMATION}

Data S1 Sexual size dimorphism dataset for body mass and carapace length

\section{REFERENCES}

Abouheif, E., and Fairbairin, D.J. (1997) A comparative analysis of allometry for sexual size dimorphism: assessing Rensch's Rule. The American Naturalist 149, 540-562. 
445 Alroy, J. (1998) Cope's rule and the dynamics of body mass evolution in North American fossil 446 mammals. Science 280, 731-734.

447 Andersson, M. (1994) Sexual Selection, Princeton University Press, Princeton.

448 Angielczyk, K.D., Burroughs, R.W., and Feldman, C.R. (2015) Do turtles follow the rules?

449 Latitudinal gradients in species richness, body size, and geographic range area of the world's 450 turtles. Journal of Experimental Zoology Part B Molecular and Developmental Evolution 00B, $451 \quad 1-25$.

452 Berry, J.F., and Shine, R. (1980) Sexual size dimorphism and sexual selection in turtles (order 453 Testudines). Oecologia 44, 185-191.

454 Blomberg, S.P., Garland, T., Jr., and garlandIves, A.R. (2003) Testing for phylogenetic signal in 455 comparative data: behavioral traits are more labile. Evolution 57, 717-745.

456 Boback, S.M., and Guyer, C. (2003) Empirical evidence for an optimal body size in snakes. 457 Evolution 57, 345-351.

458 Bonnet, X., Delmas, V., El-Mouden, H., Slimani, T., Sterijovski, B., and Kuchling, G. (2010) Is 459 sexual body shape dimorphism consistent in aquatic and terrestrial chelonians? Zoology 113, $460 \quad 213-220$.

461 Brassey, C.A., and Sellers, W.I. (2014) Scaling of convex hull volume to body mass in modern 462 primates, non-primate mammals and birds. PLoS One, 9, e91691.

463 Brassey, C.A., O’Mahoney, T.G., Kitchener, A.C., Manning, P.L., and Sellers, W.I. (2016) 464 Convex-hull mass estimates of the dodo (Raphus cucullatus): application of a CT-based mass 465 estimation technique. PeerJ 4, e1432.

466 Brown, J.H., Gillooly, J.F., Allen, A.P., Savage, V.M., and West, G.B. (2004) Toward a 467 metabolic theory of ecology. Ecology 85, 1771-1789.

468 Calder, W.A., III. (1996) Size, function, and life history. Dover Publications, Mineola.

469 Cardillo, M., Mace, G.M., Jones, K.E., Bielby, J., Bininda-Edmonds, O.R.P., Sechrest, W., 470 Orme, C.D.L., and Purvis, A. (2005) Multiple causes of high extinction risk in large mammal 471 species. Science 309, 1239-1241.

472 Ceballos, C.P., and Valenzuela, N. (2011) The role of sex-specific plasticity in shaping sexual 473 dimorphism in a long-lived vertebrate, the snapping turtle Chelydra serpentina. Evolutionary 474 Biology 38, 163-181. 
475 Ceballos, C.P., Adams, D.C., Iverson, J.B., and Valenzuela, N. (2013) Phylogenetic patterns of 476 sexual size dimorphism in turtles and their implications for Rensch's rule. Evolutionary Biology 477 40, 194-208.

478 Ceballos, C.P., and Iverson, J.B. (2014) Patterns of sexual size dimorphism in Chelonia: 479 revisiting Kinosternidae. Biological Journal of the Linnean Society 111, 806-809.

480 Ceballos, C.P., Hernández, O.E., and Valenzuela, N. (2014) Divergent sex-specific plasticity in 481 long-lived vertebrates with contrasting sexual dimorphism. Evolutionary Biology 41, 81-98.

482 Cheng, R. -C., and Kuntner, M. (2015) Disentangling the size and shape components of sexual 483 dimorphism. Evolutionary Biology 42, 223-234.

484 Chiari, Y., Wang, B., Rushmeier, H., and Caccone, A. (2008) Using digital images to reconstruct 485 three-dimensional biological forms: a new tool for morphological studies. Biological Journal of 486 the Linnean Society 95, 425-436.

487 Cox, R.M., Butler, M.A., and John-Adler, H.B. (2007) Chapter 4: the evolution of sexual size 488 dimorphism in reptiles. Sex, size and gender roles: evolutionary studies of sexual size 489 dimorphism (ed. by D.J. Fairbairn, W.U. Blanckenhorn, and T. Székely), pp. 39-49. Oxford 490 University Press, Oxford.

491 Fairbairn, D.J., Blanckenhorn, W.U., and Székely, T. (2007) Sex, size and gender roles. Oxford 492 University Press, Oxford.

493 Fairbairn, D.J. (1997) Allometry for sexual size dimorphism: pattern and process in the 494 coevolution of body size in males and females. Annual Review of Ecology and Systematics 28, $495 \quad 659-687$.

496 Feldman, A., and Meiri, S. (2013) Length-mass allometry in snakes. Biological Journal of the 497 Linnean Society 108, 161-172.

498 Feldman, A., Sabath, N., Pyron, R.A., Mayrose, I., and Meiri, S. (2016) Body sizes and 499 diversification rates of lizards, snakes, amphisbaenians and the tuatara. Global Ecology and 500 Biogeography 25, 187-197.

501 Field, D.J., Lynner, C., Brown, C., and Darroch, S.A.F. (2013) Skeletal correlates for body mass 502 estimation in modern and fossil flying birds. PLoS One 8, e82000.

503 Fitch, H.S. (1981) Sexual size differences in reptiles. Miscellaneous Publications of the Museum 504 of Natural History, University of Kansas 70, 1-72.

505 Garland, T., Harvey, P.H., and Ives, A.R. (1992) Procedures for the analysis of comparative data 506 using phylogenetically independent contrasts. Systematic Biology 41, 18-32. 
507 Gibbons, J.W., and Lovich, J.E. (1990) Sexual dimorphism in turtles with emphasis on the slider

508 turtle (Trachemys scripta). Herpetological Monographs 4, 1-29.

509 Gillooly, J.F., Brown, J.H., West, G.B., Savage, V.M., and Charnov, E.L. (2001) Effects of size 510 and temperature on metabolic rate. Science 293, 2248-2251.

511 Halámková, L., Schulte, J.A., and Langen, T.A. (2013) Patterns of sexual size dimorphism in

512 Chelonia. Biological Journal of the Linnean Society 108, 396-413.

513 Iverson, J.B. (1982) Biomass in turtle populations: a neglected subject. Oecologia 55, 69-76.

514 Iverson, J.B. (1985) Geographic variation in sexual dimorphism in the mud turtle Kinosternon

515 hirtipes. Copeia 1985, 388-393.

516 Jacobson, E.R., Weinstein, M., Berry, K., Hardenbrook, B., Tomlinson, C., and Freitas, D.

517 (1993) Problems with using weight versus carapace length relationships to assess tortoise health.

518 Veterinary Record 132, 222-223.

519 Kembel, S.W., Cowan, P.D., Helmus, M.R., Cornwell, W.K., Morlon, H., Ackerly, D.D.,

520 Blomberg, S.P., and Webb, C.O. (2010) Picante: R tools for integrating phylogeneies and

521 ecology. Bioinformatics 26, 1463-1464.

522 Lindeman, P.V. (2008) Evolution of body size in the map turtles and sawbacks (Emydidae:

523 Deirochelyinae: Graptemys). Herpetologica 64, 32-46.

524 Lovich, J.E., Ernst, C.H., and McBreen, J.F. (1989) Growth, maturity, and sexual dimorphism in 525 the wood turtle, Clemmys insculpta. Canadian Journal of Zoology 68, 672-677.

526 Lovich, J.E., and Gibbons, J.W. (1992) A review of techniques for quantifying sexual size

527 dimorphism. Growth, Development, and Aging 56, 269-281.

528 Lovich, J.E., Znari, M., Abdeljalil ait Baamrane, M., Naimi, M., and Mostalih, A. (2010)

529 Biphasic geographic variation in sexual size dimorphism of turtle (Mauremys leprosa)

530 populations along an environmental gradient in Morocco. Chelonian Conservation and Biology

$5319,45-53$.

532 Lovich, J.E., Gibbons, J.W., and Agha, M. (2014) Does the timing of attainment of maturity

533 influence sexual size dimorphism and adult sex ratio in turtles? Biological Journal of the

534 Linnean Society 112, 142-149.

535 Lynch, M. (2007) The origins of genome architecture, 1st ed. Sinauer Associates, Sunderland.

536 Martin, R.A. (1990) Estimating body mass and correlated variables in extinct mammals: travels

537 in the fourth dimension. Body size in mammalian paleobiology: estimation and biological

538 implications (ed by J. Damuth and B.J. MacFadden), pp. 49-68. University Press, Cambridge. 
539 Meiri, S., Bauer, A.M., Chirio, L., Colli, G.R., Das, I., Doan, T.M., Feldman, A., Herrera, F.-C., 540 Novosolov, M., Pafilis, P., Pincheira-Donoso, D., Powney, G., Torres-Carvajal, O., Uetz, P., and 541 Van Damme, R. (2013) Are lizards feeling the heat? A tale of ecology and evolution under two 542 temperatures. Global Ecology and Biogeography 22, 834-845.

543 Nagy, K.A., Henen, B.T., Vyas, D.B., and Wallis, I.R. (2002) A condition index for the desert 544 tortoise (Gopherus agassizii). Chelonian Conservation and Biology 4, 425-429.

545 Paradis, E., Claude, J., and Strimmer K. (2004) APE: analyses of phylogenetics and evolution in 546 R language. Bioinformatics 20, 289-290.

547 Payne, J.L., Smith, F.A., Kowalewski, M., Krause, R.A., Boyer, A.G., McClain, C.R., Finnegan, 548 S., Novack-Gottschall, P.M., and Sheble, L. (2012) A lack of attribution: closing the citation gap 549 through a reform of citation and indexing practices. Taxon 61, 1349-1351.

550 Peters, R.H. (1986) The ecological implications of body size. Cambridge University Press, 551 Cambridge.

552 Pincheira-Donoso, D., Fox, S.F., Scolaro, J.A., Ibargüengoytía, N., Acosta, J.C., Corbalán, V., 553 Medina, M., Boretto, J., Villavicencio, H.J., and Hodgson, D.J. (2011) Body size dimensions in 554 lizard ecological and evolutionary research: exploring the predictive power of mass estimation 555 equations in two Liolaemidae radiations. Herpetological Journal 21, 35-42.

556 Pritchard, P, Bacon, P., Berry, F., Carr, A., Fletemeyer, J., Gallagher, R., Hopkins, S., Lankford, 557 R., Marquez, R., Ogren, L., Pringle, W., Jr., Reichart, H., and Witham, R. (1983) Manual of sea 558 turtle research and conservation techniques, 2nd ed. (ed. by K.A. Bjorndal and G.H. Balazs), 559 Center for Environmental Education, Washington, D.C.

560 R Core Team. (2015) R: A language and environment for statistical computing. Version 3.2.0. 561 Available at: http://www.R-project.org/

562 Rising, J.D., and Somers, K.M. (1989) The measurement of overall body size in birds. The Auk 563 106, 666-674.

564 Smith, R.J., and Jungers, W.L. (1997) Body mass in comparative primatology. Journal of 565 Human Evolution, 32 523-559.

566 Stamps, J.A. (1983) Sexual selection, sexual dimorphism, and territoriality. Lizard ecology:

567 studies of a model organism (ed. by R.B. Huey, E.R. Pianka, and T.W. Schoener), pp. 169-204.

568 University Press, Cambridge.

569 Stephens, P.R., and Wiens, J.T. (2009) Evolution of sexual size dimorphisms in Emydid turtles: 570 ecological dimorphism, Rensch's Rule, and sympatric divergence. Evolution 63, 910-925. 
571 Stevenson, R.D., and Woods, W.A., Jr. (2006) Condition indices for conservation: new uses for 572 evolving tools. Integrative and Comparative Biology 46, 1169-1190.

573 Székely, T., Lislevand, T., and Figuerola, J. (2007) Sexual size dimorphism in birds. Sex, size 574 and gender roles: evolutionary studes of sexual size dimorphism (ed. by D. Fairbairn, W.

575 Blanckenhorn, and T. Székely), pp. 27-37. Oxford University Press, Oxford.

576 van Dijk, P.P., Iverson, J.B., Rhodin, A.G.J., Shaffer, H.B., and Bour, R. (2014) Turtles of the 577 world, $7^{\text {th }}$ edition: annotated checklist of taxonomy, synonymy, distribution with maps, and 578 conservation status. Conservation biology of freshwater turtles and tortoises: a compliation 579 project of the ICUN/SSC Tortoise and Freshwater Turtle Specialist Group (ed. By A.G.J. 580 Rhodin, P.C.H. Pritchard, P.P. van Dijk, R.A. Saumure, K.A. Buhlmann, J.B. Iverson, and R.A. 581 Mittermeier), Chelonian Research Monographs 5, 000.329-479.

582 van Dijk, P.P., Iverson, J.B., Shaffer, H.B., Bour, R., \& Rhodin, A.G.J. (2012) Turtles of the 583 world, 2012 update: annotated checklist of taxonomy, synonymy, distribution, and conservation 584 status. Chelonian Research Monographs 5, 243-328.

585 Warton, D.I., Duursma, R.A., Falster, D.S., and Taskinen, S. (2012) smatr 3 - an R package for 586 estimation and inference about allometric lines. Methods in Ecology and Evolution 3, 257-259.

587 Webb, T.J., and Freckleton, R.P. (2007) Only half right: species with female-biased sexual size 588 dimorphism consistently break Rensch's Rule. PLoS ONE 2, e897.

589 Werner, Y.L., Korolker, N., Sion, G., and Göçmen, B. (2016) Bermann's and Rensch's rules and 590 the spur-thighed tortoise (Testudo graeca). Biological Journal of the Linnean Society 117, 798591811.

592 Wiens, J.J., Brandley, M.C., and Reeder, T.W. (2006) Why does a trait evolve multiple times?

593 Repeated evolution of snakelike body form in squamate reptiles. Evolution 60, 123-141. 
595

596 Table 1. Summary of the datasets. The data used for phylogenetic analyses (one population per 597 species) are listed first, and the data for all populations (including multiple populations of some 598 species) follows in parentheses. Mean dimorphism index is that of Lovich \& Gibbons (1992), 599 with negative values indicating male size bias.

\begin{tabular}{|c|c|c|c|c|c|c|c|c|c|}
\hline \multirow{2}{*}{ Family } & \multirow{2}{*}{$\begin{array}{l}\text { Extant } \\
\text { Species }\end{array}$} & \multirow{2}{*}{$\begin{array}{l}\text { Mass } \\
\text { Species }\end{array}$} & \multirow{2}{*}{$\begin{array}{c}\text { SCL } \\
\text { Species }\end{array}$} & \multicolumn{2}{|c|}{$\begin{array}{c}\text { Male } \\
\text { Mean Size }\end{array}$} & \multicolumn{2}{|c|}{$\begin{array}{c}\text { Female } \\
\text { Mean Size }\end{array}$} & \multicolumn{2}{|c|}{$\begin{array}{l}\text { Mean Dimorphism } \\
\text { Index }\end{array}$} \\
\hline & & & & $\begin{array}{l}\text { Mass } \\
(\mathrm{g})\end{array}$ & $\begin{array}{l}\mathrm{SCL} \\
(\mathrm{cm})\end{array}$ & $\begin{array}{l}\text { Mass } \\
(\mathrm{g})\end{array}$ & $\begin{array}{l}\mathrm{SCL} \\
(\mathrm{cm})\end{array}$ & Mass & SCL \\
\hline Carettochelyidae & 1 & $\begin{array}{c}1 \\
(1)\end{array}$ & $\begin{array}{c}1 \\
(3)\end{array}$ & $\begin{array}{c}9500 \\
(9500)\end{array}$ & $\begin{array}{c}45.4 \\
(40.3)\end{array}$ & $\begin{array}{c}16000 \\
(16000)\end{array}$ & $\begin{array}{c}52.3 \\
(47.2)\end{array}$ & $\begin{array}{c}0.684 \\
(0.684)\end{array}$ & $\begin{array}{c}0.152 \\
(0.177)\end{array}$ \\
\hline Chelidae & 54 & $\begin{array}{c}26 \\
(36)\end{array}$ & $\begin{array}{c}39 \\
(78)\end{array}$ & $\begin{array}{c}1274 \\
(1404)\end{array}$ & $\begin{array}{c}22.8 \\
(21.9)\end{array}$ & $\begin{array}{c}1987 \\
(2114)\end{array}$ & $\begin{array}{c}25.2 \\
(24.8)\end{array}$ & $\begin{array}{c}0.502 \\
(0.484)\end{array}$ & $\begin{array}{c}0.118 \\
(0.140)\end{array}$ \\
\hline Cheloniidae & 6 & $\begin{array}{c}4 \\
(6)\end{array}$ & $\begin{array}{c}5 \\
(15)\end{array}$ & $\begin{array}{c}52132 \\
(67255)\end{array}$ & $\begin{array}{c}77.7 \\
(83.9)\end{array}$ & $\begin{array}{c}57414 \\
(74683)\end{array}$ & $\begin{array}{c}81.6 \\
(87.8)\end{array}$ & $\begin{array}{c}0.096 \\
(0.107)\end{array}$ & $\begin{array}{c}0.052 \\
(0.045)\end{array}$ \\
\hline Cheyldridae & 4 & $\begin{array}{c}2 \\
(10)\end{array}$ & $\begin{array}{l}3 \\
(9)\end{array}$ & $\begin{array}{c}22129 \\
(19396)\end{array}$ & $\begin{array}{c}44.7 \\
(40.6)\end{array}$ & $\begin{array}{c}10530 \\
(10103)\end{array}$ & $\begin{array}{c}39.1 \\
(34.9)\end{array}$ & $\begin{array}{l}-0.778 \\
(-0.713)\end{array}$ & $\begin{array}{l}-0.136 \\
(-0.152)\end{array}$ \\
\hline Dermatemydidae & 1 & $\begin{array}{c}1 \\
(4)\end{array}$ & $\begin{array}{c}1 \\
(2)\end{array}$ & $\begin{array}{c}6396 \\
(6267)\end{array}$ & $\begin{array}{c}38.2 \\
(40.7)\end{array}$ & $\begin{array}{c}6622 \\
(6617)\end{array}$ & $\begin{array}{c}34.2 \\
(41.2)\end{array}$ & $\begin{array}{c}0.035 \\
(0.060)\end{array}$ & $\begin{array}{l}-0.118 \\
(-0.001)\end{array}$ \\
\hline Dermochelyidae & 1 & $\begin{array}{c}1 \\
(2)\end{array}$ & $\begin{array}{c}1 \\
(2)\end{array}$ & $\begin{array}{c}320000 \\
(413500)\end{array}$ & $\begin{array}{c}155 \\
(161.8)\end{array}$ & $\begin{array}{c}387600 \\
(397850)\end{array}$ & $\begin{array}{c}147.1 \\
(161.5)\end{array}$ & $\begin{array}{c}0.211 \\
(-0.016)\end{array}$ & $\begin{array}{l}-0.054 \\
(-0.005)\end{array}$ \\
\hline Emydidae & 49 & $\begin{array}{c}20 \\
(68)\end{array}$ & $\begin{array}{c}48 \\
(129)\end{array}$ & $\begin{array}{c}736 \\
(640)\end{array}$ & $\begin{array}{c}17.7 \\
(17.1)\end{array}$ & $\begin{array}{c}1754 \\
(1155)\end{array}$ & $\begin{array}{c}23.4 \\
(21.8)\end{array}$ & $\begin{array}{c}1.99 \\
(1.25)\end{array}$ & $\begin{array}{c}0.386 \\
(0.315)\end{array}$ \\
\hline Geoemydidae & 72 & $\begin{array}{c}29 \\
(47)\end{array}$ & $\begin{array}{c}52 \\
(106)\end{array}$ & $\begin{array}{c}1487 \\
(1619)\end{array}$ & $\begin{array}{c}19.5 \\
(19.6)\end{array}$ & $\begin{array}{c}2835 \\
(2809)\end{array}$ & $\begin{array}{c}23.6 \\
(24.1)\end{array}$ & $\begin{array}{c}1.61 \\
(1.12)\end{array}$ & $\begin{array}{c}0.238 \\
(0.261)\end{array}$ \\
\hline Kinosternidae & 24 & $\begin{array}{c}12 \\
(22)\end{array}$ & $\begin{array}{c}23 \\
(59)\end{array}$ & $\begin{array}{c}344 \\
(304)\end{array}$ & $\begin{array}{c}14.4 \\
(13.6)\end{array}$ & $\begin{array}{c}315 \\
(300)\end{array}$ & $\begin{array}{c}13.7 \\
(13.0)\end{array}$ & $\begin{array}{c}0.059 \\
(0.098)\end{array}$ & $\begin{array}{c}-0.041 \\
(-0.046)\end{array}$ \\
\hline Pelomedusidae & 19 & $\begin{array}{c}3 \\
(4)\end{array}$ & $\begin{array}{c}4 \\
(7)\end{array}$ & $\begin{array}{c}2550 \\
(2662)\end{array}$ & $\begin{array}{c}33.1 \\
(32.8)\end{array}$ & $\begin{array}{c}3607 \\
(3255)\end{array}$ & $\begin{array}{c}32.6 \\
(32.3)\end{array}$ & $\begin{array}{c}0.637 \\
(0.387)\end{array}$ & $\begin{array}{c}-0.029 \\
(-0.025)\end{array}$ \\
\hline Platysternidae & 1 & $\begin{array}{c}1 \\
(1)\end{array}$ & $\begin{array}{c}1 \\
(2)\end{array}$ & $\begin{array}{c}367 \\
(367)\end{array}$ & $\begin{array}{c}13.2 \\
(16.7)\end{array}$ & $\begin{array}{c}306 \\
(306)\end{array}$ & $\begin{array}{c}12.2 \\
(15.1)\end{array}$ & $\begin{array}{l}-0.201 \\
(-0.201)\end{array}$ & $\begin{array}{c}-0.080 \\
(-0.098)\end{array}$ \\
\hline Podocnemididae & 8 & $\begin{array}{c}7 \\
(10)\end{array}$ & $\begin{array}{c}8 \\
(20)\end{array}$ & $\begin{array}{c}2615 \\
(2387)\end{array}$ & $\begin{array}{c}30.8 \\
(29.3)\end{array}$ & $\begin{array}{c}4289 \\
(4435)\end{array}$ & $\begin{array}{c}37.8 \\
(37.4)\end{array}$ & $\begin{array}{l}0.925 \\
(1.13)\end{array}$ & $\begin{array}{c}0.223 \\
(0.278)\end{array}$ \\
\hline Testudinidae & 68 & $\begin{array}{c}29 \\
(81)\end{array}$ & $\begin{array}{c}43 \\
(124)\end{array}$ & $\begin{array}{c}25690 \\
(15809)\end{array}$ & $\begin{array}{c}25.9 \\
(26.4)\end{array}$ & $\begin{array}{l}11508 \\
(7986)\end{array}$ & $\begin{array}{c}25.2 \\
(25.6)\end{array}$ & $\begin{array}{c}0.065 \\
(0.192)\end{array}$ & $\begin{array}{c}0.062 \\
(0.048)\end{array}$ \\
\hline Trionychidae & 27 & $\begin{array}{l}10 \\
(15)\end{array}$ & $\begin{array}{c}12 \\
(25)\end{array}$ & $\begin{array}{c}19507 \\
(17187)\end{array}$ & $\begin{array}{c}36.5 \\
(37.1)\end{array}$ & $\begin{array}{c}28373 \\
(23720)\end{array}$ & $\begin{array}{c}45.7 \\
(46.9)\end{array}$ & $\begin{array}{c}1.45 \\
(1.27)\end{array}$ & $\begin{array}{c}0.436 \\
(0.413)\end{array}$ \\
\hline All Chelonians & 335 & $\begin{array}{c}146 \\
(307)\end{array}$ & $\begin{array}{c}241 \\
(581)\end{array}$ & $\begin{array}{c}11303 \\
(10381)\end{array}$ & $\begin{array}{c}24.0 \\
(24.1)\end{array}$ & $\begin{array}{l}10221 \\
(8858)\end{array}$ & $\begin{array}{c}26.9 \\
(26.8)\end{array}$ & $\begin{array}{c}0.853 \\
(0.650)\end{array}$ & $\begin{array}{c}0.182 \\
(0.168)\end{array}$ \\
\hline
\end{tabular}

600

601 
602 Table 2. Results of standardized major axis regressions at the suborder and family levels for both 603 body mass and carapace length data without adjustment for phylogeny. Em dashes represent an 604 isometric relationship, and RR indicates Rensch's Rule. The families Pelomedusidae, 605 Cheloniidae, and the 4 monotypic families were omitted from family analyses due to insufficient 606 sample sizes, but are included in the analyses of turtle suborders (bold text).

607

\begin{tabular}{|c|c|c|c|c|c|c|c|c|c|c|}
\hline \multirow[b]{2}{*}{ Clade } & \multicolumn{5}{|c|}{ Body Mass } & \multicolumn{5}{|c|}{ Straight Carapace Length } \\
\hline & $\mathrm{n}$ & Intercept & Slope & $\begin{array}{c}95 \% \\
\text { CI }\end{array}$ & Pattern & $\mathrm{n}$ & Intercept & Slope & $\begin{array}{c}95 \% \\
\text { CI }\end{array}$ & Pattern \\
\hline Cryptodira & 110 & -0.984 & 1.081 & $\begin{array}{l}1.008 \\
1.158\end{array}$ & RR & 190 & -0.199 & 1.058 & $\begin{array}{c}0.991 \\
1.129\end{array}$ & - \\
\hline Emydidae & 20 & 0.472 & 0.826 & $\begin{array}{c}0.563 \\
1.213\end{array}$ & - & 48 & -0.178 & 1.023 & $\begin{array}{c}0.832 \\
1.256\end{array}$ & - \\
\hline Geoemydidae & 29 & -0.702 & 1.016 & $\begin{array}{c}0.795 \\
1.30\end{array}$ & - & 52 & -0.097 & 1.008 & $\begin{array}{c}0.850 \\
1.194\end{array}$ & - \\
\hline Kinosternidae & 12 & -1.278 & 1.227 & $\begin{array}{c}0.866 \\
1.738\end{array}$ & - & 23 & -0.272 & 1.136 & $\begin{array}{c}0.952 \\
1.356\end{array}$ & - \\
\hline Testudinidae & 29 & -1.826 & 1.230 & $\begin{array}{l}1.158 \\
1.306\end{array}$ & $\mathrm{RR}$ & 43 & -0.531 & 1.217 & $\begin{array}{l}1.130 \\
1.311\end{array}$ & RR \\
\hline Trionychidae & 10 & -4.560 & 1.400 & $\begin{array}{l}1.059 \\
1.851\end{array}$ & RR & 12 & -0.292 & 1.068 & $\begin{array}{c}0.705 \\
1.616\end{array}$ & - \\
\hline Pleurodira & 36 & 0.169 & 0.926 & $\begin{array}{c}0.783 \\
1.094\end{array}$ & - & 51 & -0.578 & 1.005 & $\begin{array}{c}0.863 \\
1.170\end{array}$ & - \\
\hline Chelidae & 26 & 0.274 & 0.916 & $\begin{array}{c}0.738 \\
1.136\end{array}$ & - & 39 & -0.182 & 1.057 & $\begin{array}{c}0.876 \\
1.275\end{array}$ & - \\
\hline Podocnemididae & 7 & -0.961 & 1.050 & $\begin{array}{c}0.595 \\
1.852\end{array}$ & - & 8 & 0.199 & 0.890 & $\begin{array}{c}0.550 \\
1.442\end{array}$ & - \\
\hline
\end{tabular}


608 Table 3. Results of standardized major axis regressions at the suborder (bold text) and family 609 levels using phylogenetic independent contrasts. Em dashes represent an isometric relationship 610 and RR indicates Rensch's Rule.

611

612

613

\begin{tabular}{|c|c|c|c|c|c|c|c|c|}
\hline \multirow[b]{2}{*}{ Clade } & \multicolumn{4}{|c|}{ Body Mass } & \multicolumn{4}{|c|}{ Straight Carapace Length } \\
\hline & $\mathrm{n}$ & Slope & $\begin{array}{c}95 \% \\
\text { CI }\end{array}$ & Pattern & $\mathrm{n}$ & Slope & $\begin{array}{c}95 \% \\
\text { CI }\end{array}$ & Pattern \\
\hline Cryptodira & 110 & 1.148 & $\begin{array}{l}1.065 \\
1.237\end{array}$ & $\mathrm{RR}$ & 190 & 1.121 & $\begin{array}{l}1.046 \\
1.202\end{array}$ & $\mathrm{RR}$ \\
\hline Emydidae & 20 & 1.008 & $\begin{array}{c}0.681 \\
1.493\end{array}$ & - & 48 & 1.024 & $\begin{array}{c}0.832 \\
1.259\end{array}$ & - \\
\hline Geoemydidae & 29 & 1.305 & $\begin{array}{l}1.021 \\
1.666\end{array}$ & $\mathrm{RR}$ & 52 & 1.157 & $\begin{array}{c}0.944 \\
1.418\end{array}$ & - \\
\hline Kinosternidae & 12 & 1.495 & $\begin{array}{l}1.103 \\
2.026\end{array}$ & $\mathrm{RR}$ & 23 & 1.102 & $\begin{array}{c}0.943 \\
1.289\end{array}$ & - \\
\hline Testudinidae & 29 & 1.212 & $\begin{array}{l}1.137 \\
1.293\end{array}$ & $\mathrm{RR}$ & 43 & 1.235 & $\begin{array}{c}1.118 \\
1366\end{array}$ & $\mathrm{RR}$ \\
\hline Trionychidae & 10 & 1.602 & $\begin{array}{l}1.215 \\
2.112\end{array}$ & $\mathrm{RR}$ & 12 & 1.190 & $\begin{array}{c}0.766 \\
1.850\end{array}$ & 一 \\
\hline Pleurodira & 36 & 0.861 & $\begin{array}{c}0.709 \\
1.046\end{array}$ & - & 51 & 0.962 & $\begin{array}{c}0.817 \\
1.133\end{array}$ & - \\
\hline Chelidae & 26 & 0.855 & $\begin{array}{c}0.679 \\
1.076\end{array}$ & - & 39 & 1.056 & $\begin{array}{c}0.878 \\
1.271\end{array}$ & - \\
\hline Podocnemididae & 7 & 1.023 & $\begin{array}{c}0.594 \\
1.760\end{array}$ & - & 8 & 0.866 & $\begin{array}{c}0.592 \\
1.267\end{array}$ & - \\
\hline
\end{tabular}


614 Figure 1. Standardized major axis regression of male and female body size measurements of 615 turtle species. Body mass (Fig. 1A) supported Rensch's rule, and straight carapace length (Fig. 616 1B) supported an isometric relationship between body size and sexual size dimorphism. Dashed 617 lines represent isometry.
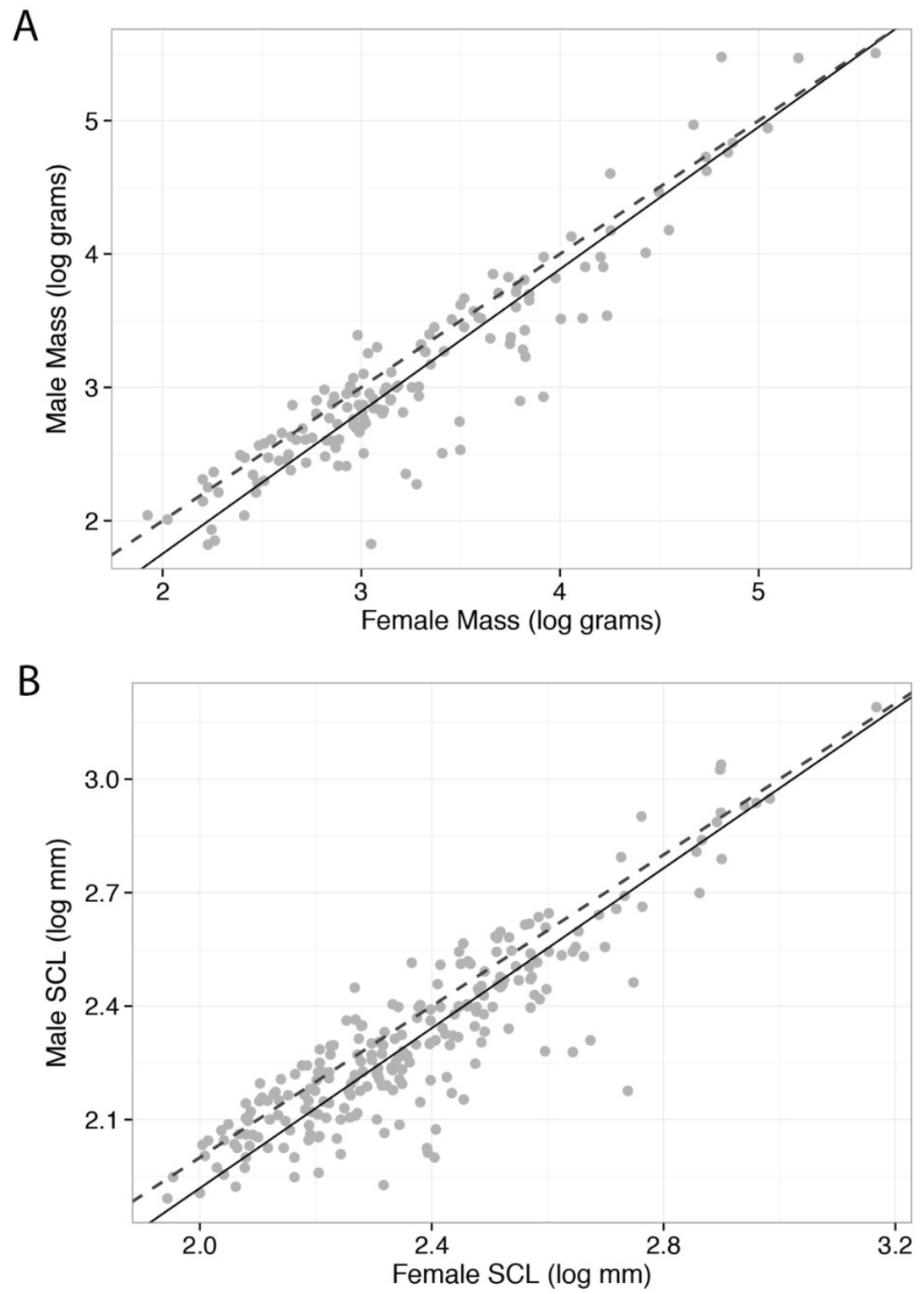

618

619 
621 Figure 2. Phylogenetic independent contrasts regressed using standardized major axis regression for male and female body size measurements of turtle species. Body mass (Fig. 2A) and straight carapace length (Fig. 2B) both supported Rensch's Rule. Dashed lines represent isometry, and lines of best fit are forced through the origin. At this scale, mass and length body size

625 measurements yielded comparable results.

626
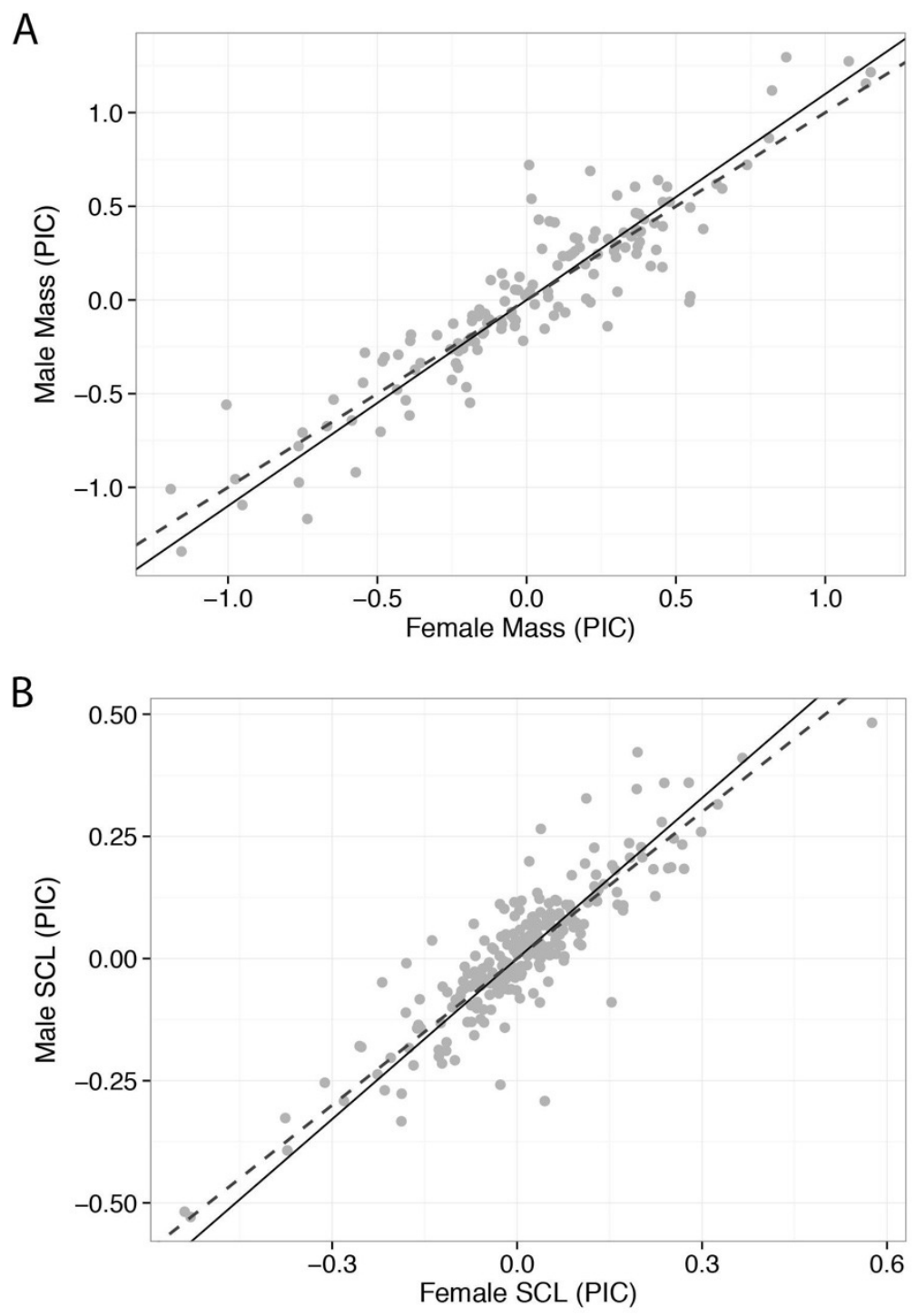

627 
631 Figure 3. Regression relationship between body mass and straight carapace length in turtles. 632 Multiple populations for some species are included. Males are represented by open circles (in 633 blue) and females are closed circles (in red). Males and females did not differ in slope and the 634 difference in $r^{2}$ was marginally non-significant.

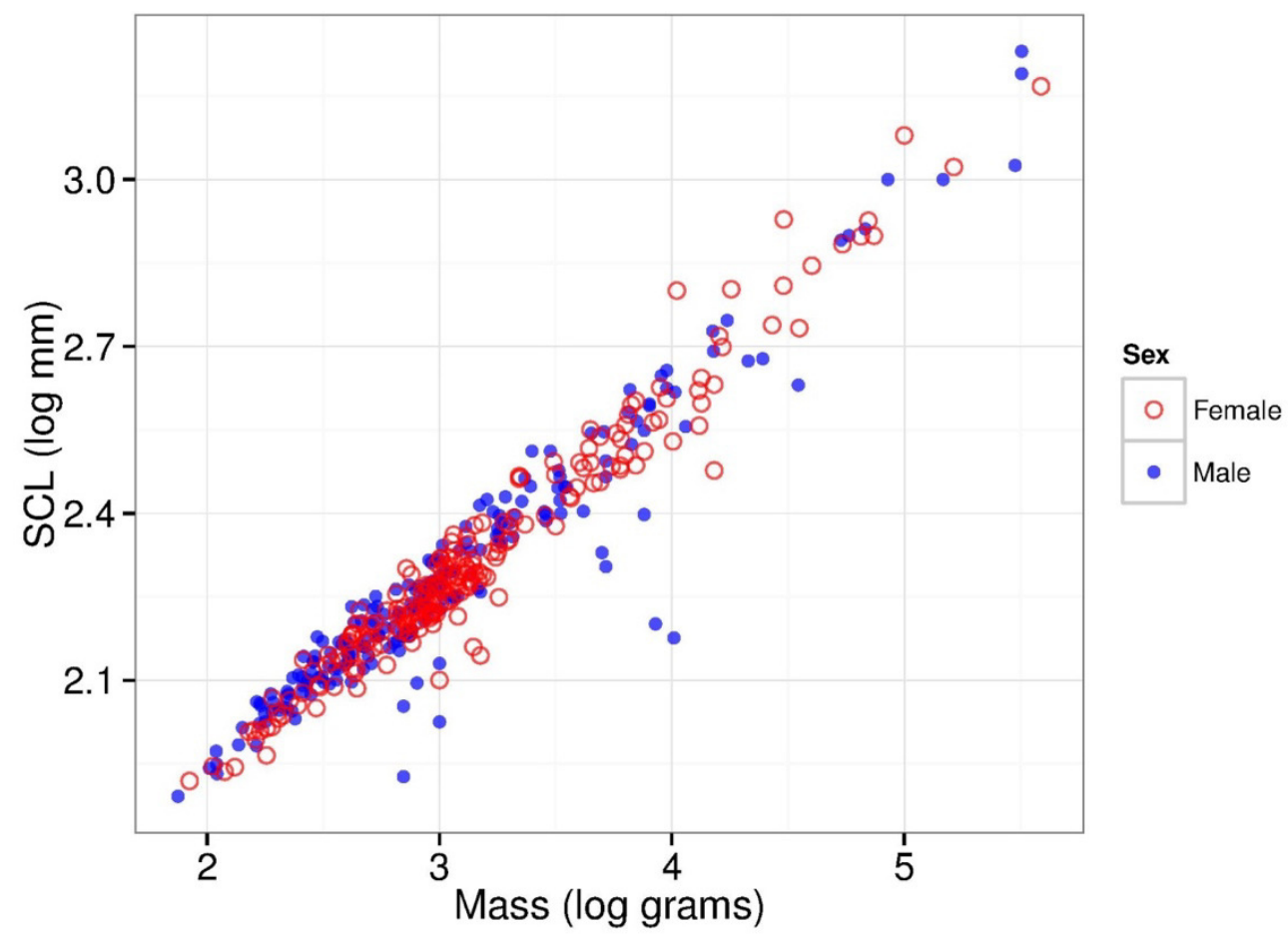

